\title{
APRENDIZAGEM DA LÍNGUA PORTUGUESA COMO SEGUNDA LÍNGUA: DESAFIOS E PROPOSTAS DE ENSINO
}

\author{
APRENDIZAGEM DA LÍNGUA PORTUGUESA COMO SEGUNDA LÍNGUA: DESAFIOS E \\ PROPOSTAS DE ENSINO
}

Cleidiane da Penha Segura de Melo

E.M.E.I.E.F Bilíngue Porto Velho, Porto Velho, RO, Brasil. E-mail: seguracleidiane@gmail.com

\section{Emanuelly Mariana Trindade Guimaráes}

Escola Estadual Dona Rosa Frigger Piovezan, Comodoro, MT, Brasil. E-mail: emanuelly.mtg@gmail. com

\section{Luciana Raimunda de Lana Costa}

Escola Estadual Dona Rosa Frigger Piovezan, Comodoro, MT, Brasil. E-mail: luciana.costa@unemat.br

DOI: https://doi.org/10.46550/amormundi.v2i6.125

Recebido em: 22.08.2021

Aceito em: 10.10.2021

\begin{abstract}
Resumo: $\mathrm{O}$ ensino da Língua Portuguesa para alunos surdos tem sido um desafio para os professores, visto que estes precisam utilizar métodos diferenciados dos já utilizados para os ouvintes. $\mathrm{O}$ ensino direcionado aos surdos deve se basear na modalidade visual-gestual, em contraposiçáo à modalidade de ensino dos ouvintes, a qual é oral-auditiva. Sendo assim, o objetivo deste texto é destacar as principais metodologias utilizadas no ensino da Língua Portuguesa para surdos. Para isto, foram utilizadas pesquisas bibliográficas com o intuito de colaborar para a pesquisa acadêmica sobre melhoria da qualidade da aprendizagem do aluno surdo, no contexto da educação bilíngue, que privilegia a Língua de Sinais como recurso fundamental para a educação de surdos. Para tal reflexão, valemo-nos de autores como Pereira (2009), Quadros (1999) dentre outros autores que discutem a realidade vivenciada por estudantes surdos na aquisição da Língua Portuguesa como segundo idioma. O texto ainda discute os desafios que o docente ouvinte enfrenta para adquirir a segunda língua (Libras) para se comunicar com o estudante náo ouvinte. Além de alternativas possíveis a serem implantadas não apenas pela escola, mas por toda a sociedade e os poderes públicos responsáveis por implementarem açôes que visem a (des) construção de conceitos referentes à aprendizagem da Língua Portuguesa como segunda língua para alunos surdos e a Libras para toda a comunidade escolar.
\end{abstract}

Palavras-chave: Ensino. Processo de Aprendizagem. Língua Portuguesa como L2. Educação Bilíngue para surdos.

Abstract: The teaching of Portuguese language to deaf students has been a challenge for teachers, as they need to use different methods from those already used for hearing students. The teaching aimed at the deaf should be based on the visual-gesture modality, as opposed to the hearing modality, which is oral-auditory. Therefore, the aim of this text is to highlight the main methodologies used in teaching the Portuguese language to the 
deaf. For this, bibliographical researches were used in order to contribute to academic research on improving the quality of learning for deaf students, in the context of bilingual education, which privileges Sign Language as a fundamental resource for deaf education. For such reflection, we use authors such as Pereira (2009), Quadros (1999) among other authors who discuss the reality experienced by deaf students in the acquisition of Portuguese as a second language. The text also discusses the challenges that the hearing teacher faces to acquire the second language (Libras) to communicate with the non-hearing student. In addition to possible alternatives to be implemented not only by the school, but by society as a whole and the public authorities responsible for implementing actions aimed at (de) building concepts related to learning Portuguese as a second language for deaf students and Libras for the entire school community.

Keywords: Teaching. Learning process. Portuguese language as L2. Bilingual Education for the Deaf.

\section{Reflexóes introdutórias}

O que importa a surdez da orelha quando a mente ouve? A verdadeira surdez, a incurável surdez, é a da mente. (Ferdinand Berther apud GESSER, A., 2009, p.

63).

o longo de toda a história, o ensino da Língua Portuguesa como segunda língua para alunos surdos tem sido um desafio para os professores que atuam em escolas regulares, e até mesmo para aqueles que atuam em escolas bilíngues dada a necessidade de conhecimento e exercício de Libras.

O objetivo deste apanhado de reflexóes, portanto é destacar as principais metodologias utilizadas no ensino da Língua Portuguesa para surdos, com enfoque nas estratégias didáticas que contribuem para o ensino da Língua Portuguesa como segunda língua, doravante L2.

A maioria dos professores que atuam em escolas regulares, não sabem Libras e, consequentemente, sentem dificuldades na sua práxis pedagógica devido à falta de domínio e fluência em Libras. Falta-lhes, portanto, estratégias de ensino, e acabam não atingindo resultados satisfatórios.

Para os professores que atuam em escolas bilíngues, a dificuldade consiste em selecionar e utilizar as estratégias que possibilitem uma melhoria no ensino aprendizagem, visto que a falta de metodologia adequada acaba dificultando o aprendizado do aluno surdo. Mediante esta realidade, o presente trabalho visa a apresentar as dificuldades encontradas no processo de ensino-aprendizagem da Língua Portuguesa como L2, buscando alternativas para amenizar as dificuldades encontradas por docentes no ensino da L2.

Outro aspecto salientado durante o texto é a dificuldade e, até mesmo, a resistência da sociedade como um todo em aderir a Libras enquanto fenômeno linguístico a ser exercitado/ aprendido desde o nascimento da criança surda e sua prática ainda na alfabetização. Este texto, portanto, em um primeiro momento, coloca o leitor a par do contexto em que se encontra o ensino de Libras no país, nas escolas. Em segundo momento, aponta possibilidades e estratégias para amenizar o impacto sofrido pela criança surda em contato direto e constante com uma escola monolíngue. $\mathrm{O}$ texto ainda salienta a importância da conscientizaçáo por toda a comunidade escolar e da sociedade para a adequação de si quanto ao exercício e ao currículo da Libras nas escolas.

\section{Processo de aquisiçáo da língua portuguesa como 12}


Durante o processo de aprendizagem, ocorre a interlíngua, caracterizada como a língua de transição entre a Língua de Sinais e a Língua Portuguesa, em sua modalidade escrita. É recorrente que o surdo, durante a construção de textos, escreva uma frase em português da mesma forma que esta se organiza em Libras, portanto cabe ao professor estabelecer as diferenças, visto que a Língua de Sinais possui modalidade gestual-visual (ou espaço-visual), em oposição à modalidade dos ouvintes, que é oral-auditiva, o que implica com que ambas as línguas se organizem de forma diferente.

Segundo Quadros (1999), a aquisição de L2 sofre influências de questôes internas e externas. Quanto às influências externas, vale destacar a importância da interação para a aquisição da Língua Portuguesa. Estes temas também são abordados por Santos (2011, p.5), ao tratar sobre a pré-escrita, a escrita e a reescrita, caracterizando-as da seguinte forma:

A pré-escrita diz respeito ao planejamento ou à preparação para a escrita. Envolve leitura, avaliação e pensamento, que devem ser realizados antes da elaboração da escrita. Assim, baseia-se num contexto determinado: situaçóes vivenciadas, conversaçóes sobre fatos reais, discussóes significativas para o aluno, entre outros. Quanto à escrita, é um processo que ocorre espontaneamente através da transposição de ideias para o papel por meio de símbolos gráficos e, normalmente, apresenta uma relaçáo direta com uma língua de sinais. Já a reescrita é um processo de reelaboração e ocorre devido à intervenção do professor; representa o feedback para o aluno surdo, possibilitando a reflexáo e o controle sobre as hipóteses experimentadas.

Este processo de aprendizagem ocorre primeiramente em Libras para posteriormente ser apreendido em Língua Portuguesa. O aluno surdo precisa compreender o significado, adquirir vocabulário, ter conhecimentos sobre o tema que está estudando, participando da construção de tal tema. Segundo Formagio e Lacerda (2016, p.23):

Somente a partir deste exercício é possível levar os alunos à produção escrita, considerando os conhecimentos sobre o tema, sobre o gênero e sobre o posicionamento deles em relação a este mesmo tema. Para escrever, é necessário que se tenha o que dizer! Este percurso de ensino/aprendizagem é inverso ao tradicionalmente desenvolvido na escola. Esta dimensão discursiva torna inviável a aplicação de uma metodologia igual a surdos e ouvintes, e consequentemente, nos mesmos espaços das aulas de português.

Outros elementos também são citados por Quadros (1999) com relação à aquisição de L2, os quais são: o ambiente, as estratégias de aprendizagem, estilos de aprendizagem, idade, motivação e fatores afetivos.

$\mathrm{O}$ ambiente escolar em que o aluno está inserido faz toda a diferença no processo de aquisição de uma língua, no caso a Língua Portuguesa. Todo o espaço escolar precisa ser bilíngue, desde o porteiro da escola, até o diretor, todos precisam propiciar esse ambiente bilíngue, possibilitando ao aluno um lugar de convívio com os seus pares, sua cultura e uma inserção natural em sua língua materna, bem como metodologias que favoreçam um ensino que contemple as duas línguas num processo contínuo de aquisição tanto de uma língua como da outra.

A escola torna-se, portanto, um espaço linguístico fundamental, pois normalmente é o primeiro espaço que a criança surda entra em contato com a língua brasileira de sinais. Por meio da língua de sinais, a criança vai adquirir linguagem. Isso significa que ela estará concebendo um mundo novo usando uma língua que é 
percebida e significada ao longo do seu processo. Todo esse processo possibilita a significação por meio da escrita que pode ser na própria língua de sinais, bem como, no português. (QUADROS; SCHMIEDT,2006, p.22).

No ambiente escolar bilíngue (Libras e Língua Portuguesa) isso é possível, pois o aluno surdo está inserido nas duas línguas, possibilitando a construção de significados. Eis a principal razão para que a comunidade escolar desloque o próprio discurso em relação à aquisição linguística do surdo, ou seja, deixe de encarar o fenômeno como patologia e perceba que, para o surdo, a aprendizagem da Língua Portuguesa equivale à dificuldade de um ouvinte em aprender alemão ou qualquer outro idioma estrangeiro.

Logo, não é difícil perceber que só quem consegue dominar as duas línguas consegue ensinar uma delas. Além do fato de que a inserção com a língua estudada proporciona maior aprendizagem.

\section{A família como facilitadora da aquisiçáo da L2}

A importância da família para o processo educacional se explicita em vários artigos da Lei de Diretrizes e Bases da Educação Nacional (Lei No 9.394/96), que estabelecem o dever das escolas se articularem com as famílias, visando à participação dos pais na vida escolar de seu filho, com o intuito de fortalecer os vínculos familiares.

A boa relação familiar reverbera num melhor trabalho do professor em sala de aula, principalmente se o ambiente familiar interage com a Língua de Sinais e valoriza a cultura surda. Assim, os resultados sáo melhores no processo de ensino, utilizando atividades que contemplem a realidade do aluno surdo.

Em vista disso, cabe à escola promover um ambiente linguístico e sociocultural que garanta à família interagir com os seus filhos, respeitando sua cultura e língua e possibilitando a participação no processo de ensino. No caso das famílias de surdos, vale considerar as seguintes situaçôes: alunos surdos, filhos de pais ouvintes, e alunos surdos, filhos de pais surdos. Sendo assim, haverá alunos estimulados desde criança a sua língua materna em sua própria cultura, inseridos na comunidade surda, como também alunos que foram estimulados desde pequenos à oralidade e que seu primeiro contato com a Libras acontece na escola.

Além disso, haverá também surdos os quais são filhos de pais surdos que chegam à escola apenas com gestos caseiros, pois não são inseridos na comunidade. Nestes casos, é necessário selecionar as estratégias de ensino de acordo com o estilo de aprendizagem do aluno e seu histórico de aquisição da linguagem.

\section{Escola, espaço de busca de estratégias}

Quanto às estratégias e estilos de aprendizagem, Quadros e Schmiedt (2006, p.29) citam os objetivos que devem ser trabalhados pelo professor em sala de aula, os quais são:

Desenvolver o uso de estratégias específicas para resoluçấo de problemas; exercitar o uso de jogos de inferência; trabalhar com associações; desenvolver as habilidades de discriminação visual; explorar a comunicação espontânea; ampliar constantemente vocabulário; oferecer constantemente literatura impressa na escrita em sinais; proporcionar atividades para envolver a criança no processo de 
alfabetização como autora do próprio processo.

$\mathrm{O}$ uso destas estratégias de ensino pautadas em uma metodologia que utilize recursos visuais contribui para melhores resultados em relação à didática do professor e consequentemente à aprendizagem de seus alunos. Por meio de um ensino bilíngue, tais estratégias contribuem para propiciar um ambiente favorável à aprendizagem. Ao iniciar uma aula com apresentação de uma imagem, inicia-se um processo de estimulação à exploração de conhecimento prévio e experiências vividas relacionadas à imagem, possibilitando a participação dos alunos na construção do conhecimento.

Muitos acreditam, ainda hoje, que a surdez acarrete dificuldades de compreensão na leitura e de produção na escrita. No entanto, uma análise do processo de ensino da leitura e da escrita de alunos surdos leva a acreditar que muitos dos resultados insatisfatórios, obtidos com a maior parte dos alunos, náo decorrem de dificuldades de lidar com os símbolos escritos, mas da falta de uma língua constituída com base na qual possam construir a escrita. (PEREIRA, 2009, p. 12).

Outra situação a ser considerada no ensino aprendizado do aluno surdo é a idade e a motivação. Os surdos, em sua maioria, chegam à escola atrasados ou ainda ficam reprovados ano após ano em uma escola que não propicia uma educação bilíngue, tornando o ensino da Língua Portuguesa quase impossível, acarretando atraso na educação, o que implica em surdos desmotivados devido à repetência escolar. Consequentemente, os alunos surdos possuem idades avançadas em relação à idade dos ouvintes, e isso provoca a perda de interesse pelos estudos.

A possibilidade de compreender o que lê e ter acesso a diferentes tipos de texto é, em si, fator de motivação para o aluno surdo, que, por muito tempo, ficou limitado a textos empobrecidos, semântica e morfossintaticamente. Vale lembrar, no entanto, que, principalmente no início do processo, o acesso ao conteúdo dos textos vai ser possível por meio da interpretação na Língua de Sinais, o que vai resultar em ampliação do conhecimento de mundo. Também o conhecimento de língua portuguesa vai ser ampliado se o professor, ao interpretar os textos, aproveitar para mostrar aos alunos como um conteúdo em Língua de Sinais é expresso em português. (PEREIRA, 2009, p. 49).

A realidade é que os alunos chegam à escola e iniciam o processo de alfabetização tardiamente, pois iniciam seus estudos em uma escola em que a língua majoritária é a Língua Portuguesa, sem acessibilidade linguística, sem profissionais preparados.

Outro fator que contribui para o atraso é a família que demora aceitar a Libras como língua do seu filho, e por isso opta por uma escola regular em que a proposta de ensino não é bilíngue, o que acarreta atraso no processo de alfabetização. E sabemos que

Situações em que as crianças ouvintes vivenciam diariamente e que respondem pela aquisição incidental do seu conhecimento são, muitas vezes, limitadas para as crianças surdas em função da falta de uma língua partilhada com os familiares ouvintes. (PEREIRA, 2009, p. 12).

Consoante a isso, há que se considerar também o fator emocional do aluno surdo em relação à aprendizagem, pois as experiências vividas na escola e, até mesmo em casa, têm forte relação com a aprendizagem. Como esperar que um aluno se interesse pelos estudos se ele náo é motivado a isso? Ou pior, muitas vezes, acontece o inverso: surdos são ridicularizados pela forma como se expressam no português escrito, rejeitados em grupos devido a sua condição de não 
ouvir, subestimados em relação a sua capacidade de aprendizagem. Em outras palavras,

Na Língua Portuguesa, há também um fator emocional em jogo, que diz respeito a uma memória muito negativa retratada a partir da experiência de vários surdos alfabetizados. Uma aluna surda contou que sempre que ela tem que escrever fica muito nervosa, tem vergonha de errar, resiste, não tem prazer ao fazê-lo e sempre fica preocupada com as reaçóes de quem vai ler o que ela escreve. Curiosamente, disse-me que a relação com a língua inglesa é diferente. Reconhece que sabe muito menos inglês do que português, mas que se sente mais à vontade para usar a língua inglesa. (GESSER, 2009, p. 56).

As vivências e experiências dos alunos são parte do processo de aprendizado da Língua de Sinais e da Língua Portuguesa como Segunda Língua. Tais influências externas acima mencionadas são fundamentais para o ensino e aprendizagem do português em sua modalidade escrita. Levando em consideraçáo estas influências, é possível repensar acerca das metodologias adequadas para o ensino bilíngue.

\section{Sala de aula, açóes possíveis}

O documento oficial que rege, hoje, a prática discursiva em sala de aula a Base Nacional Comum Curricular, doravante BNCC, garante o respeito à diversidade linguística ao afirmar que "existem muitas línguas ameaçadas de extinção no país e no mundo, o que nos chama a atenção para a correlação entre repertórios culturais e linguísticos, pois o desaparecimento de uma língua impacta significativamente a cultura" (BRASIL, 2018, p.70). Assim, a BNCC esclarece que

No Brasil com a Lei no 10.436, de 24 de abril de 2002, oficializou-se também a Língua Brasileira de Sinais (Libras), tornando possível, em âmbito nacional, realizar discussóes relacionadas à necessidade do respeito às particularidades linguísticas da comunidade surda e do uso dessa língua nos ambientes escolares. (BRASIL, 2018, p.70).

A Libras é uma dessas riquezas em diversidade linguística. Apesar de necessitar ainda de uma força-tarefa entre o poder público, família e escola, a existência da necessidade da prática de Libras em sala de aula é real, concreta. Mas o que impede/impediria o professor, a escola fazerem uso da prática bilíngue em sala?

Apesar de existir uma atribuição legal que visa garantir uma aprendizagem significativa ao aluno surdo, ainda existem lacunas a serem preenchidas, como os conceitos e os paradigmas que necessitam de ser desconstruídos, práticas docentes avulsas, desconectadas de um todo, sem o fundamento das práticas pedagógicas que lhes conferem sentido e direção.

As escolas, além de inclusivas, também precisam garantir a Língua de Sinais como língua de instrução aos surdos, o que é de fundamental importância com professores bilíngues, fluentes em Libras. Entretanto, este fato está atrelado a outra situação igualmente ampla: políticas públicas que garantam não apenas a formação do professor, mas principalmente acesso à Libras. Importante salientar que tal formação não se faz em um cursinho ou apenas em formação contínua. É necessário que as políticas públicas percebam que Libras deve ser um direito e um dever na escola. Ao professor comprometido, cabe a aprendizagem e prática dela.

Algo fundamental para que os alunos compreendam conteúdos em Língua Portuguesa é o conhecimento linguístico e de mundo, os quais constituem o conhecimento prévio, tão importante para que façam relaçóes de sentido, com a integração de informaçóes novas somadas 
àquelas que eles (alunos) já possuem previamente.

No entanto, é importante destacar que, na maioria das vezes, as crianças surdas não participam de conversas em sua própria casa, principalmente quando sua família é constituída somente de ouvintes, o que resulta no empobrecimento de conhecimento prévio, dificultando, assim, o processo de aprendizagem de outra língua.

O processo relatado acima acontece porque o ensino da Libras, ainda que seja a segunda Língua oficial no país, ainda não é aceita pela maioria das famílias, apesar dos vários meios de difusão como cursos oferecidos pelas secretarias de educação, universidades, cursos técnicos, igrejas e outros. A língua dos surdos continua sendo vista/ formulada individualmente apenas como gestos desorganizados pautados na crença familiar de que o surdo pode desenvolver a fala.

Neste sentido, a surdez já é encarada como diferença, pois a relação da família com o surdo passa a ser diferenciada desde o princípio. Enquanto o surdo tem como sua primeira língua a LIBRAS, a família tem a Língua Portuguesa. Aproximar esses dois universos é o desafio da escola, da sociedade e (por que não?) do poder público.

Em vista disso, a alfabetização deve ser encarada como um processo de construção de conhecimento, assim como um processo de interação, no qual existem atores que estabelecem papéis muito importantes em relação ao ensino-aprendizagem do surdo, sendo estes atores: a família e a comunidade escolar, mas também pode-se incluir todos aqueles que fazem parte do cotidiano do surdo, os quais de alguma forma contribuem nessa construção de conhecimentos.

Quanto ao papel do professor na educação dos surdos, é importante que este partilhe a mesma língua do aluno, pois isto contribui para o desenvolvimento de conhecimento prévio, facilitando a compreensão do significado do que leem, o que contribui para o que o surdo deixe de ser meramente decodificador da escrita e passe a compreender os textos, mesmo que desconheça alguns vocábulos.

Segundo Solé (1998), no que diz respeito ao processo de compreensão do texto pelos alunos surdos, cabe ao professor incentivá-lo a ler, auxiliando na descoberta de diversas utilidades da leitura em situaçôes que promovam a aprendizagem significativa, contribuindo com os recursos necessários para que o aluno possa enfrentar a atividade de leitura com segurança e confiança, além de transformar o aluno em leitor ativo, o qual faz uso de seus conhecimentos e experiências que o levam a criar expectativas e questionamentos.

O acesso a diferentes tipos de texto, assim como a compreensão destes por parte dos alunos surdos podem contribuir para o gosto pela leitura e escrita, pois quanto mais o aluno é exposto ao conhecimento linguístico e a leitura de mundo, mais fácil será o processo de compreensão da linguagem escrita. Isto porque

a importância de se possibilitar condiçóes para que a criança surda tenha consciência da utilidade e do prazer da língua escrita. Segundo o pesquisador, isso pode ser conseguido lendo-se para ela contos, escrevendo-lhe bilhetes e cartóes, lendo com ela, consultando anúncios, rótulos, etiquetas e livros na sua presença, fazendo-a ver a utilidade da escrita nas atividades da vida diária, como compras e passeios. Para o mesmo autor, a leitura é a principal fonte de informação para a criança surda adquirir a linguagem escrita. A ênfase deve estar em ler, não em ensinar a ler. $\mathrm{Na}$ medida em que a criança seja exposta de maneira significativa a textos variados, de crescente nível de descontextualização, irá adquirindo a linguagem escrita de maneira natural. (TOVAR, 2000, Apud Pereira, 2009, p.28) 
Portanto, entendemos que a aquisição da L2 se constitui em um processo que envolve conhecimento linguístico e conhecimento de mundo, práticas de ensino que utilizem a Libras no ensino da L2 e não a simples decodificação de palavras, ampliação de vocabulário mediante ao acesso a variados tipos de texto. É necessário, portanto, que haja um esforço conjunto entre a comunidade escolar e família do aluno surdo, no intuito de contribuir para a aprendizagem da L2, tanto na leitura quanto na escrita, pois todo aprendizado que contemple a inserção ou estreita relação com a realidade do estudante possui maiores e melhores possibilidades de sucesso e produz efeitos diretos na vida do estudante (e por que não?) daqueles que o cercam.

\section{Consideraçóes finais}

A prática pedagógica da escola e a aprendizagem da Língua Portuguesa como L2 por parte dos surdos perpassam por um ponto comum de reflexão a desmistificaçáo do processo de aquisição da linguagem. Faz-se necessário que a comunidade escolar perceba que Língua Portuguesa é uma língua estrangeira para o aluno e, como tal, necessita de professores que dominem os dois idiomas: Português e Libras.

Algo que não pode ser negado é a necessidade de se difundir a LIBRAS entre a comunidade escolar, pois assim há maiores chances de reverberar em melhores resultados em relação ao ensino aprendizagem da Língua Portuguesa como L2. Isto contribui inclusive para o ensino de outras disciplinas, pois o português, em sua modalidade escrita, é fundamental para a comunicação e o estabelecimento das relaçóes sociais.

Da mesma forma, quanto mais estratégias didáticas que levem em conta as características do surdo, mais os métodos têm a possibilidade de melhores resultados, os quais em sua maioria são embasados em recursos visuais, e, ainda mais, os professores conseguem atingir resultados positivos no exercício de sua profissáo, o que contribui para a formaçáo de surdos cada vez mais conscientes e em igualdade de condição com as demais pessoas.

Se não pensarmos em estratégias de ensino visual, que contemplem as duas línguas, Libras e a Língua Portuguesa, o ensino será frustrante para o aluno surdo, pois ele fica distante das atividades que sáo desenvolvidas em sala de aula, o que, na maioria das vezes, é provocado pela falta de preparo do professor; os problemas de comportamento e de socialização passam a ser maiores, já que o docente demonstra insegurança frente ao aprendizado desse aluno.

Percebemos, portanto, que todas as demandas e desafios enfrentados pela escola em relação a Libras estão atrelados a como o universo escolar (e até mesmo o acadêmico), a família e a sociedade incluem e entendem a Libras. Muitas pessoas ainda a enxergam como algo de difícil compreensão. Esquecem-se que toda língua para o falante não nativo oferece a mesma dificuldade. Esquecem -se que a Libras é considerada a segunda língua do Brasil e como tal precisa ser melhor considerada pela população brasileira.

Uma língua com tamanha importância e abrangência ainda não é ensinada em todas as escolas e nem é considerada como uma matéria do componente curricular. O currículo nas escolas (na sua grande maioria) preocupa-se em ensinar o Inglês ou Espanhol como segunda comunicação de seus alunos, deixando, mais uma vez, de lado os indivíduos surdos que sáo presentes na realidade escolar. 


\section{Referências}

BRASIL. Ministério da Educação. Base Nacional Comum Curricular. Brasília, 2018.

FORMAGIO, C. L.S. Práticas pedagógicas do ensino de português como segunda língua para alunos surdos no ensino fundamental. In: LACERDA, C.B.F.; SANTOS, L.F.; MARTINS, V.R.O. (Org.). Escola e Diferença: caminhos para educação bilíngue de surdos. 1ed. São Carlos: EdUFSCar, 2016, v.1, p. 169-241. Disponível em: http://portal.sme.prefeitura.sp.gov. br/Portals/1/Files/19642.pdf. Acesso em: 20 de maio de 2016.

GESSER, A. Libras? Que língua é essa?: crenças e preconceitos em torno da língua de sinais e da realidade surda. São Paulo: Parábola Editorial, 2009.

LEI No 9.394, DE 20 DE DEZEMBRO DE 1996. Disponível em: https://www2.senado.leg. br/bdsf/bitstream/handle/id/70320/65.pdf?sequence=3. Acesso em: 03 de agosto de 2016 .

PEREIRA, M. C. C. (org.). Leitura, escrita e surdez. São Paulo: FDE, 2009.

QUADROS, R. M. de. Aquisição de L2: o contexto da pessoa surda. In: III SEMINÁRIO INTERNACIONAL DE LINGUÍSTICA, 1996, Porto Alegre. Anais do III Seminário Internacional e Linguística. Porto Alegre: Gráfica Epecê, 1999. v. 1.p.67-74. Disponível em: http://docplayer.com.br/13976510-Aquisicao-de-12-o-contexto-da-pessoa-surda-i-ronicemuller-de-quadros-ii.html. Acesso em: 18 de julho de 2016.

QUADROS, R. M. de. Idéias para ensinar português para alunos surdos / Ronice Muller Quadros, Magali L. P. Schmiedt. - Brasília: MEC, SEESP, 2006. 120pDisponível em:http:// portal.mec.gov.br/seesp/arquivos/pdf/port_surdos.pdf Acesso em: 26 de julho de 2016.

SANTOS, F. M. A. O processo de aprendizagem da escrita do português por surdos: singularidades e estratégias facilitadoras. Inventário (Universidade Federal da Bahia. Online), v.8, p.1-16, 2011. Disponível em: http://www.inventario.ufba.br/08/O\%20 processo\%20de\%20aprendizagem\%20corrigido.pdf. Acesso em 24/07/2016.

SOLÉ, I. Estratégias de leitura. 6. ed. Porto Alegre: ArtMed, 1998. 